\title{
Penentuan Waktu Optimum Perbaikan Komponen Mesin Cing Fong $H$ Di PT Ajinomoto Indonesia, Mojokerto Menggunakan Analisis Reliabilitas Dengan Pendekatan Fungsi Copula
}

\author{
Linda Wulansari Taryanto, Agus Suharsono,dan Haryono \\ Departemen Statistika, Fakultas Matematika, Komputasi dan Sains Data, \\ Institut Teknologi Sepuluh Nopember (ITS) \\ Jalan Arief Rahman Hakim, Surabaya 60111 \\ E-mail: , linda.wulansa@gmail.com ${ }^{(1)}$,agus_s@statistika.its.ac.id ${ }^{(2)}$, haryono@statistika.its.ac.id ${ }^{(3)}$
}

\begin{abstract}
Abstrak-Mesin Cing Fong $\boldsymbol{H}$ merupakan salah satu mesin yang digunakan pada proses produksi tepung bumbu Sajiku di PT Ajinomoto Indonesia. Pada mesin Cing Fong $\mathrm{H}$, terdapat dua komponen yang memiliki fungsi penting yaitu cutter dan selenoid. Apabila terjadi masalah terhadap salah satu dari komponen tersebut maka kemasan akan rusak (cacat) atau tidak dapat tercetak sehingga mesin mengalami breakdown hal tersebut terjadi karena komponen saling mempengaruhi (dependen). karena itu, perlu diadakan maintenance atau perawatan mesin sehingga tidak terjadi breakdown saat mesin sedang berproduksi. Penelitian ini bertujuan untuk menentukan waktu optimum perbaikan atau pergantian komponen mesin Cing Fong $H$ di PT Ajinomoto Indonesia berdasarkan analisis reliabilitas dengan pendekatan Copula sehingga dapat mengurangi biaya perawatan dan memaksimumkan produksi dengan pendekatan ilmu statistik. Berdasarkan hasil analisis diperoleh kesimpulan bahwa lifetime komponen cutter dan selenoid pada mesin Cing Fong $H$ berdistribusi weibull 2 parameter. Pada perhitungan nilai dependensi didapatkan nilai $\mathbf{- 0 , 0 0 9 5 2 3 8 1}$ dan menghasilkan Copula terbaik dengan nilai parameter Copula terkecil sebesar 0,01887 yaitu pada Copula clayton. Sehingga didapatkan model reliabilitas dan didapatkan plot yang menujukan bahwa keandalan suatu mesin akan mengalami penurunan seiring bertambahnya waktu pakai mesin. Berdasarkan model reliabilitas didapatkan waktu preventive maintenace komponen yang optimum dapat dilakukan dalam kurun waktu 795 jam sampai dengan 1000 jam.
\end{abstract}

Kata Kunci-Cing Fong H, Clayton, Copula, Maintenance, Reliabilitas, Weibull

\section{PENDAHULUAN}

$\mathrm{P}$ eningkatan jumlah konsumsi tepung bumbu di Indonesia, mengakibatkan banyaknya produsen tepung bumbu instan bermunculan. PT Ajinomoto Indonesia sebagai produsen tepung bumbu terbesar di Indonesia ikut ambil bagian dalam memperkenalkan tepung bumbu Instan di Indonesia. PT Ajinomoto memproduksi tepung bumbu instan dengan nama Sajiku. Salah satu tahapan pembuatan tepung bumbu sajiku yaitu pengisian tepung kedalam kemasan. Pada proses pengisian Sajiku dibuat dalam beberapa kemasan berbeda, di antaranya kemasan 80 gram, 250 gram, dan 1 kilogram. Pada industri makanan, kualitas suatu produk sangatlah diperhatikan mulai dari proses penerimaan bahan baku hingga pengemasan. Kemasan menjadi hal yang sangat penting karena mengandung banyak informasi dan menjaga kualitas produk. Mesin Cing Fong $H$ merupakan salah satu mesin yang digunakan pada proses produksi tepung bumbu Sajiku. Mesin tersebut memiliki peran yang penting dalam pembuatan kemasan tepung bumbu serbaguna ukuran 80 gram. Sehingga waktu breakdown mesin mempengaruhi jumlah produksi, dimana setiap menit mesin menghasilkan 45 sachet.

Pada mesin Cing Fong H, terdapat dua komponen yang memiliki fungsi penting yaitu cutter dan selenoid. Apabila terjadi masalah terhadap salah satu dari komponen tersebut maka kemasan akan rusak (cacat) atau tidak dapat tercetak sehingga mesin mengalami breakdown hal tersebut terjadi karena komponen saling mempengaruhi (dependen). Oleh karena itu, perlu diadakan maintenance atau perawatan mesin sehingga tidak terjadi breakdown saat mesin sedang berproduksi. Kebijakan maintenance yang dilakukan oleh PT Ajinomoto Indonesia yaitu perventive maintenance dan corrective maintenance, dimana perventive maintenance dilakukan satu minggu sekali pada komponen cutter dan satu bulan sekali untuk keseluruhan bagian mesin. Sebagai bentuk evaluasi dan peningkatan performance komponen mesin Cing Fong $H$, dapat dilakukan penelitian menggunakan analisis reliabilitas.

Pada dasarnya analisis reliabilitas merupakan suatu metode untuk mengetahui umur suatu mesin sehingga dapat ditentukan kapan mesin memerlukan maintenance atau perawatan. Dalam suatu sistem terdapat komponen yang saling mempengaruhi. Apabila salah satu komponen gagal maka akan mempengaruhi laju kegagalan komponen lain. Fungsi distribusi bersama dapat dibentuk dari variabel random yang dependen. Fungsi tersebut dapat diperoleh menggunakan Copula. Copula yang dikemukakan oleh Sklar (1959), menjelaskan bahwa jika terdapat suatu fungsi distribusi bivariat dan fungsi marginalnya, maka akan diperoleh fungsi yang dapat menghubungkan fungsi distribusi bivariat dengan fungsi-fungsi marginalnya [1]. Pendapat lain menjelaskan bahwa Copula adalah fungsi yang menggabungkan fungsi distribusi bersama dan fungsi distribusi marginalnya, yang merupakan alat yang ampuh untuk memodelkan ketergantungan secara multivariat [2]. Pada penelitian sebelumnya menyatakan bahwa dalam reliabilitas, ketergantungan antara variabel acak hampir secara eksklusif dimodelkan oleh Gauss (normal atau Gaussian) Copula [3]. An, Yin, dan He (2016) menyatakan bahwa dengan menggunakan teori Copula untuk melakukan pemodelan reliabilitas sistem mekanis dan ekspektasinya dari umur produk mekanis dan struktur variabel yang terkait secara terpisah, yang mengurangi kesulitan pemodelan probabilitas dan analisis multivariat, dan membuat proses pemodelan dan analisis lebih jelas. Penelitian ini bertujuan untuk menentukan waktu optimum perbaikan atau pergantian komponen mesin Cing Fong $H$ di PT Ajinomoto 
Indonesia berdasarkan analisis reliabilitas dengan pendekatan Copula sehingga dapat mengurangi biaya perawatan dan memaksimumkan produksi dengan pendekatan ilmu statistik.

\section{TINJAUAN PUSTAKA}

\section{A. Reliabilitas}

Reliabilitas adalah probabilitas suatu produk akan beroperasi atau bekerja dengan fungsinya selama periode waktu tertentu di bawah kondisi operasi yang sesuai (seperti suhu, beban, volt) tanpa kegagalan [4]. $\mathrm{F}_{\mathrm{i}}(\mathrm{t})$ adalah fungsi distribusi $\mathrm{T}_{\mathrm{i}}$, sehingga fungsi Reliabilitas masing-masing komponen adalah $\mathrm{R}_{\mathrm{i}}(\mathrm{t})=1-\mathrm{F}_{\mathrm{i}}(\mathrm{t})$, dengan fungsi reliabilitas sistem adalah $\mathrm{R}(\mathrm{t})$ [5]. Berikut ini merupakan fungsi padat probabilitas (PDF) distribusi Weibull,

$$
f(t)=\frac{m}{\theta}\left(\frac{t}{\theta}\right)^{m-1} \exp \left[-\left(\frac{t}{\theta}\right)^{m}\right]
$$

dengan fungsi reliabilitas sebagai berikut,

$$
R(t)=\exp \left[-\left(\frac{t}{\theta}\right)^{m}\right]
$$

dan Mean time to failure (MTTF) sebagai berikut,

$$
M T T F=\theta \Gamma\left(1+\frac{1}{m}\right)
$$

keterangan:

$m=$ Parameter bentuk

$\theta=$ parameter skala

$\mathrm{t}=$ waktu ke- $\mathrm{t}$

\section{B. Korelasi Tau Kendall}

Koefisien korelasi Tau Kendall didapatkan berdasarkan peringkat pada hasil amatan dan memiliki nilai dari -1 sampai dengan +1 . Salah satu perbedaan yang paling penting antara $\hat{\tau}$ dan $r_{s}$ adalah bahwa $\hat{\tau}$ suatu penduga tidak bias untuk parameter populasi, sedangkan statistik sampel $r_{s}$ tidak memberikan dugaan untuk koefisen korelasi peringkat suatu populasi [5]. Sehingga Tau Kendall dapat di definisikan sebagai berikut [6].

$$
\tau=\frac{c-d}{c+d}=\frac{c-d}{\left(\begin{array}{l}
n \\
2
\end{array}\right)}
$$

dimana

$\mathrm{c}$ : jumlah korkodan pasangan

$\mathrm{d}$ : jumlah pasangan sumbang

$\mathrm{n}$ : jumlah pengamatan

\section{Copula Archimedian}

Berdasarkan Evidence theory, pengkajian dependensi dalam reliabilitas suatu sistem dilakukan agar analisis yang dihasilkan lebih akurat [7]. Pada penelitian menyatakan bahwa reliabilitas suatu sistem dimana dua proses bersifat independen tidak memberikan reliabilitas sistem yang akurat, hal tersebut terjadi karena ada ketergantungan antara dua proses degradasi [8]. Copula adalah fungsi yang menghubungkan distribusi marginal univariat menjadi distribusi multivariat, fungsi tersebut merupakan fungsi distribusi bersama dari peubah acak seragam. Copula terdiri atas 4 keluarga. Beberapa keluarga Copula diantaranya adalah Copula

Archimedian, Copula Elips, Copula Bivariate Extreme Value, dan Copula Marshal-Olkin. Salah satu keluarga Copula yang populer yaitu keluarga archimidian. Copula Archimedian merupakan Copula yang memungkinkan mempunyai struktur dependensi yang lebih luas. Dengan Copula Archimedian, beberapa Copula dapat dibangkitkan dengan fungsi generator. Dalam bentuk umum, Copula Archimedian mempunyai bentuk sebagai berikut:

$$
C_{x}\left(u_{1} \cdot u_{2}\right)=\phi^{(-1)}\left(\phi\left(u_{1}\right), \phi\left(u_{2}\right)\right)
$$

Berikut merupakan anggota dari keluarga Copula archimedian.

\section{a. Copula Gumbel}

Copula Gumber merupakan Copula yang memiliki tail dependensi atas. Fleksibilitas Copula Archimedean diberikan oleh fungsi generator $\Phi$, sehingga Copula gumbel mempunyai fungsi generator sebagai berikut,

$$
\phi(u)=(-\log (u))^{\frac{1}{\theta}}, \theta \in(0,1]
$$

dengan fungsi Copula bivariat

$$
C\left(u_{1}, u_{2}\right)=\exp \left\{-\left[\left(-\log \left(u_{1}\right)\right)^{\frac{1}{\theta}}+\left(-\log \left(u_{2}\right)\right)^{\frac{1}{\theta}}\right]^{\theta}\right\}
$$

b. Copula Clayton

Copula clayton merupakan Copula yang memiliki tail dependensi bawah. Fleksibilitas Copula Archimedean diberikan oleh fungsi generator $\Phi$, sehingga Copula clayton mempunyai fungsi generator sebagai berikut,

$$
\phi(u)=\frac{u^{-\theta}-1}{\theta}, \theta \geq 0
$$

dengan fungsi Copula bivariat

$$
C\left(u_{1}, u_{2}\right)=\left(u_{1}^{-\theta}+u_{2}^{-\theta}-1\right)^{-\frac{1}{\theta}}
$$

c. Copula Frank

Copula Frank merupakan Copula yang tidak memiliki tail dependensi. Fleksibilitas Copula Archimedean diberikan oleh fungsi generator $\Phi$, sehingga fungsi generatornya adalah sebagai berikut.

$$
\phi(u)=-\ln \left(\frac{e^{-\theta u}-1}{e^{-\theta}-1}\right), \theta \in[1 . \infty)
$$

dengan fungsi Copula bivariat

$$
C\left(u_{1}, u_{2}\right)=-\frac{1}{\theta} \ln \left(1+\frac{\left(e^{-\theta u_{1}}-1\right)\left(e^{-\theta u_{2}}-1\right)}{e^{-\theta}-1}\right)
$$

\section{Uji Distribusi}

Dalam pengujian distribusi dilakukan sebagai langkah sebelum menentukan elemen reliabilitas. Uji Anderson-Darling merupakan salah satu tes yang digunakan untuk menguji distribusi dari suatu sampel data. Hipotesis dari uji AndersonDarling adalah sebagai berikut.

$\mathrm{H}_{0}$ : Data mengikuti distribusi tertentu

$\mathrm{H}_{1}$ : Data tidak mengikuti distribusi tertentu

Statistika uji Anderson-Darling dinyatakan dalam persamaan berikut.

$$
A^{2}=-N-2 \sum_{(i=1)}^{N}\left[\frac{(2 i-1)}{2 N} \ln \left(F\left(t_{i}\right)\right)+\left(1-\frac{2 i-1}{2 N}\right) \ln \left(1-F\left(t_{i}\right)\right)\right]
$$

Keterangan

$\mathrm{N}$ : ukuran sampel

$\mathrm{F}\left(\mathrm{t}_{\mathrm{i}}\right)$ : nilai fungsi distribusi komulatif, $\mathrm{t}_{\mathrm{i}}=1,2,3, \ldots, \mathrm{N}$ 
INFERENSI, Vol. 1(1), September. 2018, ISSN: 0216-308X

Keputusan diambil dengan membandingkan statistik uji terhadap nilai kritis $(\mathrm{CV})$.

Tabel 1. Perhitungan $P$-value

\begin{tabular}{ll}
\multicolumn{1}{c}{$\mathrm{A}^{2}$} & \multicolumn{1}{c}{ Rumus $P$-value } \\
\hline $\mathrm{A}^{2} \geq 0,6$ & $\mathrm{P}=\exp \left(1,2937-5.709\left(\mathrm{~A}^{2}\right)+0,0186\left(\mathrm{~A}^{2}\right)\right)^{2}$ \\
$0,34<\mathrm{A}^{2}<0,6$ & $\mathrm{P}=\exp \left(10,9177-4,279\left(\mathrm{~A}^{2}\right)-1,38\left(\mathrm{~A}^{2}\right)\right)^{2}$ \\
& $\mathrm{P}=1-\exp \left(--8,318-42,796\left(\mathrm{~A}^{2}\right)-\right.$ \\
$0,2<\mathrm{A}^{2}<0,34$ & $\left.59,938\left(\mathrm{~A}^{2}\right)\right)^{2}$ \\
$\mathrm{AD} \leq 0,2<\mathrm{A}^{2}<$ & $\mathrm{P}=1-\exp \left(-13,436+101,14\left(\mathrm{~A}^{2}\right)-\right.$ \\
0,34 & $\left.223,73\left(\mathrm{~A}^{2}\right)\right)^{2}$ \\
\hline
\end{tabular}

\section{E. Penduga parameter}

Prosedur penduga parameter untuk Copula archimidean dapat dilakukan dengan menggunakan pendekatan tau kendall yang dihitung melalui persamaan berikut [8].

$$
\tau=1+4 \int_{0}^{1} \frac{\phi(u)}{\phi^{\prime}(u)}
$$

Estimasi parameter untuk Copula Archimedian dengan pendekatan Tau Kendall adalah sebagai berikut.

Tabel 2. Estimasi Parameter

\begin{tabular}{|c|c|}
\hline $\begin{array}{c}\text { Jenis } \\
\text { Copula }\end{array}$ & Estimasi Parameter \\
\hline Clayton & $\tau=\frac{\gamma}{\gamma+2}$ maka $\theta_{c}=\frac{2 \tau}{1-\tau}$ \\
\hline Gumbel & $\tau=1-\theta$ maka $\theta=1-\tau$ \\
\hline Frank & $\tau=1+4 \frac{D_{1}(\alpha)-1}{\alpha}, D_{1}(\alpha)=$ fungsi Debye \\
& $D_{1}(\alpha)=\left(\frac{1}{\alpha}\right) \int_{0}^{\alpha}\left(\frac{t}{e^{t}-1}\right) d t$ \\
\hline
\end{tabular}

Sumber [9]

\section{F. Ekspetasi Biaya}

Optimasi waktu dan biaya preventive maintenance berdasarkan usia pakai (lifetime) dapat diperoleh dengan menggunakan rumus sebagai berikut [6].

$$
A V C\left(t_{p}\right)=\frac{C_{f} \times F_{T}\left(t_{p}\right)+C_{P} \times\left(1-F_{T}\left(t_{p}\right)\right)+C_{D} \times \int_{0}^{t p} F_{T}(t) d t}{t_{p}}
$$

Dengan keterangan sebagai berikut,

$C_{p} \quad$ : Cost of Preventive

$\mathrm{C}_{\mathrm{f}} \quad$ : Cost of Failure

$\mathrm{C}_{\mathrm{D}} \quad$ : Cost of Delay time

$\left(t_{p}\right)$ : Fungsi reliabilitas mesin

$t_{p} \quad:$ Waktu preventive

$\mathrm{F}\left(\mathrm{t}_{\mathrm{p}}\right) \quad$ : Merupakan1-R( $\left.\mathrm{t}_{\mathrm{p}}\right)$

\section{G. Mesin Cing Fong $H$}

Proses awal produksi tepung bumbu sajiku dimulai dari penerimaan material pembuat tepung bumbu. Proses yang kedua yaitu proses ware house matreial, sleving and metal catching material, killing egg, penimbangan material, pencampuran bahan baku, penyaringan, pengisian ke dalam kemasan, dan yang terakhir pengepakan. Pada proses pengemasan dibagi menjadi beberapa kemasan yaitu kemasan 80 gram, 250 gram, dan 1 kilogram. Mesin Cing Fong $H$ merupakan salah satu mesin pencetak kemasan 80 gram. Mesin ini memiliki banyak komponen, beberapa komponen penting yang sering mengalami kerusakan adalah cutter, selenoid, dan limit switch. Ketika limit switch di nyalakan (on) maka mesin akan menyala dan selenoid akan berjalan. Selenoid digunakan untuk menjalankan hamer, dimana hamer berfungsi untuk mencetak kemasan sachet. Kemasan sachet yang telah tercetak dan di isi oleh tepung bumbu kemudian dibuat proporasi antara sachet dan setelah terbentuk sepuluh sachet maka sachet di potong sehingga terpisah dengan sachet berikutnya. Pembuatan proporasi dan pemotongan sachet menggunakan satu komponen yaitu cutter. Berikut merupakan gambar dari ketiga komponen .

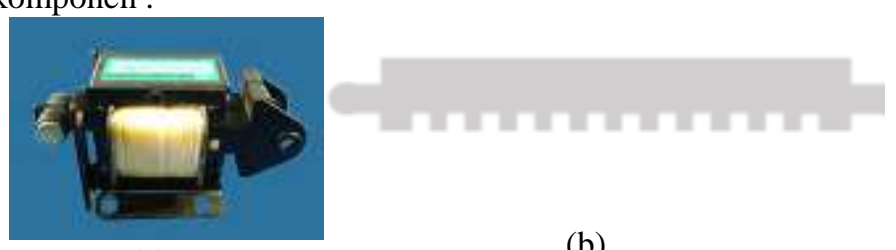

(a)

(b)

Sumber gambar a www.google.com

Gambar 1. (a) Koponen Selenoid dan (b) Komponen Cutter

\section{METODOLOGI PENELITIAN}

\section{A. Sumber Data}

Pada penelitian ini, data yang digunakan adalah data sekunder dari data lifetime komponen - komponen mesin Cing Fong $H$ yaitu cutter dan selenoid,. Mesin Cing Fong $H$ merupakan mesin pengemas tepung bumbu serbaguna kemasan 80 gram di PT Ajinomoto Indonesia. Data yang digunakan kurun waktu bulan Juli 2010 sampai dengan bulan Februari 2016.

\section{B. Variabel Penelitian}

Variabel yang digunakan dalam penelitian ini ialah waktu antar kerusakan komponen mesin Cing Fong $H$ yaitu cutter dan selenoid. Stuktur data yang digunakan dalam penelitian ini adalah sebagai berikut.

\begin{tabular}{|c|c|c|}
\hline \multirow{2}{*}{$\begin{array}{l}\text { Kegagalan } \\
\text { ke-n }\end{array}$} & \multicolumn{2}{|c|}{ Usia Pakai (lifetime) } \\
\hline & $\begin{array}{c}\text { Komponen } 1 \\
\text { (Cutter })\end{array}$ & $\begin{array}{c}\text { Komponen } 2 \\
\text { (Selenoid })\end{array}$ \\
\hline 1 & $\mathrm{Y}_{1,1}$ & $\mathrm{Y}_{2,1}$ \\
\hline 2 & $\mathrm{Y}_{1,2}$ & $\mathrm{Y}_{2,2}$ \\
\hline . & . & . \\
\hline$P_{n}$ & $Y_{1, p}$ & $\mathrm{Y}_{2, \mathrm{p}}$ \\
\hline
\end{tabular}

Tabel 3. Variabel Penelitian

\section{Langkah Analisis Data}

Metode analisis yang digunakan dalam penelitian adalah sebagai berikut.

1. Mendeskripsikan data lifetime komponen mesin cing fong $H$

2. Menentukan distribusi marginal, yaitu tipe distribusi $F_{i}(t)$ dari satuan lifetime.

3. Mentransformasi data kedalam bentuk Uniform $[0,1]$ sesuai dengan teori Sklar pada tahun 1959.

4. Mencari nilai dependensi yang didapatkan dengan melakukan uji korelasi Tau Kendall. 
5. Mendapatkan nilai estimasi parameter Copula yang didapatkan dengan pendekatan Tau Kendall.

6. Memilih fungsi Copula yang sesuai untuk fungsi reliabilitas dapat menggambarkan karakteristik yang relevan dari masing-masing unit lifetime dengan baik.

7. Mendapatkan model reliabilitas dengan membuat persamaan fungsi reliabilitas yang telah masukan persamaan Copula yang terpilih kedalam persamaan reliabilitas.

8. Menghitung reliabilitas sistem

9. Mendapatkan nilai waktu optimum dan biaya minimum dengan cara memasukan nilai-nilai biaya seperti $C_{p}, C_{f}, C_{D}$ kedalam rumus AVC dan menghitung AVC pada saat t tertentu.

10. Membuat Kesimpulan.

\section{HASIL DAN PEMBAHASAN}

\section{A. Karakteristik Data}

Usia pakai suatu komponen menunjukan usia pakai suatu mesin, Begitu pula dengan keandalan suatu mesin. komponen yang sering mengalami kegagalan akan mempengaruhi kinerja komponen lain dan kinerja mesin. Untuk mencegah terjadinya suatu kegagalan, di perlukan suatu perawatan (maintenance) terhadap komponen-komponen dalam mesin sehingga dapat mengurangi kerugian akibat kerusakan mesin. Karakterisitik suatu data menggambarkan keadaan komponen secara umum. Karakteristik sebuah komponen dapat dilihat berdasarkan statistika deskriptif dari data variabel usia pakai. Statistika deskriptif data variabel usia pakai dapat di tunjukan pada Tabel 4.

Tabel 4. Statistika Deskriptif

\begin{tabular}{ccccc}
\hline Variabel & Min & Max & Mean & Varains \\
\hline Cutter & 24 & 22872 & 3248 & 34683237 \\
Selenoid & 72 & 10392 & 2513.6 & 9291659 \\
\hline
\end{tabular}

Berdasarkan Tabel 4 dapat diketahui bahwa rata-rata dari usia pakai komponen cutter pada bulan Juli 2010 sampai dengan bulan Februari 2016 lebih tinggi dibandingkan rata-rata usia pakai dari komponen solenoid. Waktu kerusakan mesin Cing Fong $H$ bervariasi, hal ini juga ditunjukan dari selisih yang besar antara nilai minimum dan nilai maksimum masingmasing komponen.

\section{B. Uji Distribusi}

Penentuan distribusi data komponen merupakan langkah awal untuk menentukan elemen reliabilitas suatu komponen. Berdasarkan data yang telah diperoleh dari PT. Ajinomoto Indonesia mengenai usia pakai komponen cutter dan selenoid, didapatkan bahwa distribusi yang sesuai adalah distribusi weibull 2P. Dengan menggunakan hipotesis sebagai berikut.

$\mathrm{H}_{0}: \mathrm{F}(\mathrm{x})=\mathrm{F}_{\mathrm{n}}(\mathrm{x})$ (Distribusi data sesuai dengan distribusi dugaan)

$\mathrm{H}_{1}: \mathrm{F}(\mathrm{x}) \quad \neq \mathrm{F}_{\mathrm{n}}(\mathrm{x})$ (Distribusi data tidak sesuai sesuai dengan distribusi dugaan)

didapatkan hasil pengujian sebagai berikut.
Tabel 5. Uji Distribusi

\begin{tabular}{lllll}
\hline Variabel & AD & $\mathrm{D}_{15,0,05}$ & P-value & Keputusan \\
\hline Selenoid & 0,258 & 0,337 & $>0,250$ & H0 gagal ditolak \\
Cutter & 0,228 & 0,338 & $>0,251$ & H0 gagal ditolak \\
\hline
\end{tabular}

Berdasarkan pengujian, didapatkan hasil gagal tolak $\mathrm{H} 0$ dengan toleransi kesalahan sebesar 0,05 yang berarti bahwa data sesuai dengan distribusi dugaan (Weibull 2P). Berikut merupakan nilai parameter yang di dapat,

Tabel 6. Parameter Distribusi

\begin{tabular}{ccc}
\hline variabel & Shape $(\mathrm{m})$ & Scale $\theta$ \\
\hline cutter & 0,64324 & 2238,318 \\
selenoid & 0,86762 & 2326,651 \\
\hline
\end{tabular}

hasil parameter distribusi pada tabel 4.3 kemudian digunakan pada model reliabilitas dua komponen.

\section{Pemeilihan Copula Terbaik}

Pemilihan Copula terbaik yang akan digunakan dalam pembuatan model reliabilitas dapat dilihat berdasarkan nilai parameter setiap Copula. Pada penelitian ini Copula yang digunakan merupakan Copula dari keluarga Achimedian, sehingga parameter Copula didapatkan dari pendekatan tau kendall. Sebelum dilakukan perhitungan parameter terlebih dahulu dilakukan perhitungan korelasi, perhitungan korelasi dilakukan dengan metode tau kendall dan didapatkan nilai dependensi sebesar $-0,00952381$. Setelah didapatkan nilai korelasi didapatkan hasil perhitungan nilai parameter yang ditunjukan pada Tabel 7

\begin{tabular}{ll}
\multicolumn{2}{c}{ Tabel 7 Nilai Parameter Copula } \\
\hline Copula & parameter \\
\hline Clayton & $-0,01887$ \\
Gumbel & 1,00952 \\
Frank & 1,04383 \\
\hline
\end{tabular}

Berdasarkan Tabel 7 didapatkan hasil bahwa nilai estimasi parameter Copula kecil adalah Copula Clayton. Sehingga dapat disimpulkan bahwa Copula terbaik untuk memodelkan fungsi reliabilitas adalah Copula Clayton.

\section{Model Reliabilitas}

Berdasarkan hasil pengujian distribusi komponen, estimasi parameter Copulan dan didapatkan Copula terbaik, dengan menggunakan fungsi reliabilitas sebagai berikut,

$$
R(t)=1-F_{1}(x)-F_{1}(x)+C\left(F_{1}(x), F_{1}(x) ; \gamma\right)
$$

didapatkan fungsi reliabilitas $(\mathrm{R}(\mathrm{t}))$ sebagai berikut.

$$
\begin{aligned}
& R(t)=\left(e^{-\left(\frac{t}{2238,318}\right)^{0,643}}\right)+\left(e^{-\left(\frac{t}{2326,651}\right)^{0,867}}\right)-1 \\
&+\left(\left(\left(1-e^{-\left(\frac{t}{2238,318}\right)^{0,643}}\right)^{0,018}\right)\right. \\
&+\left.\left(\left(1-e^{-\left(\frac{t}{2326,651}\right)^{0,867}}\right)^{0,018}\right)-1\right)^{\frac{1}{0,018}}
\end{aligned}
$$

Setelah didapatkan fungsi reliabilitas, selanjutnya dengan memasukan nilai $\mathrm{t}$ (waktu) tertentu diperoleh hasil plot dari reliabilitas yang disajikan pada Gambar 2. Pada Gambar 2 
menunjukkan nilai reliabilitas kedua komponen sesuai perhitungan yang telah dilakukan. Pada Gambar 2 sumbu horizontal pada grafik menujukan nilai waktu dalam satuan jam sedangkan sumbu vertikal menunjukkan reliabilitas kedua komponen. Nilai reliabilitas kedua komponen terlihat menurun atau semakin kecil dari waktu ke waktu. Sehingga, dapat dinyatakan bahwa semakin lama komponen-komponen tersebut digunakan, maka keandalan komponen tersebut semakin kecil. Nilai keandalan yang semakin kecil, mengindikasikan sistem perbaikan (maintenance) yang tidak optimal. Berikut merupkan gambar scatterplot nilai reliabilitas terhadap waktu,

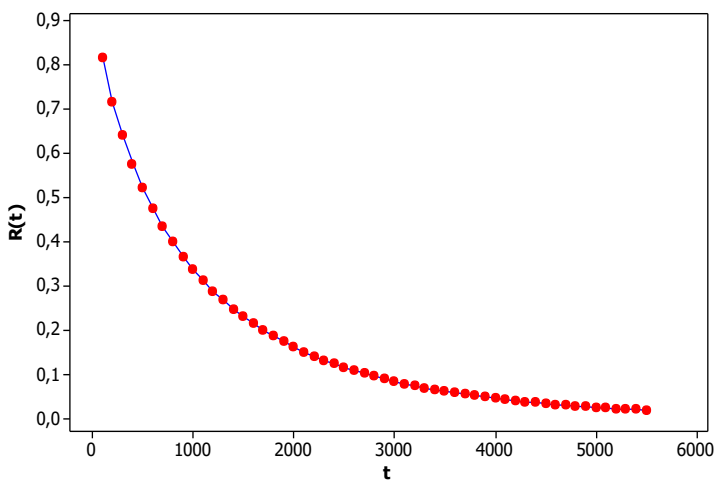

Gambar 2. Scatterplot nilai reliabilitas terhadap waktu setelah diketahui model reliabilita dari komponen selenoid dan cutter, langkah selanjutnya mencari maintenance model.

\section{E. Maintenance Model}

Dalam preventive maintenance biaya yang nantinya akan timbul adalah hal yang penting dalam penentuan waktu optimum maintenance. Dimana waktu yang optimum adalah disaat biaya yang dikeluarkan minimum. Berikut adalah nilai $\mathrm{C}_{\mathrm{P}}$ (Cost of Preventive), $\mathrm{C}_{\mathrm{f}}$ (Cost of Failure) dan $\mathrm{C}_{\mathrm{D}}$ (Cost of Delay time) yang disajikan pada Tabel 4.5.

Tabel 8. Nilai $C_{P}$ dan $C_{f}$

\begin{tabular}{lr}
\hline Biaya produksi /jam & Rp 5.018 .112 \\
$\mathrm{C}_{\mathrm{f}}$ & $\mathrm{Rp} 121.097 .788$ \\
$\mathrm{Cp}$ & $\mathrm{Rp} 2.536 .056$ \\
$\mathrm{C}_{\mathrm{D}}$ & $\mathrm{Rp} 2.509 .056$ \\
\hline
\end{tabular}

Tabel Lanjutan 8. Nilai $C_{P}$ dan $C_{f}$

Setelah mengetahui nilai $C_{P}, C_{D}$, dan $C_{f}$, selanjutnya mensuptitusikan ke dalam persamaan (2.19) sebagai berikut,

$$
\begin{aligned}
\operatorname{AVC}(\mathrm{tp})=\frac{\operatorname{Rp~} 121.097 .688 \times F_{T}(t p)}{t p} \\
+\frac{\operatorname{Rp~} 2.536 .056 \times\left(1-F_{T}(t p)\right)}{t p} \\
+\frac{\operatorname{Rp} 2.509 .056 \times \int_{0}^{t p} F_{T}(t) d t}{t p}
\end{aligned}
$$

persamaan di atas digunakan untuk menghitung biaya maintenance. Dengan memasukan nilai tp tertentu, diperoleh hasil yang kemudian dibuat plot, dimana plot tersebut dijadikan landasan untuk menentukan waktu optimum preventive maintenance. Berikut merupakan gambar Plot AVC terhadap tapi.

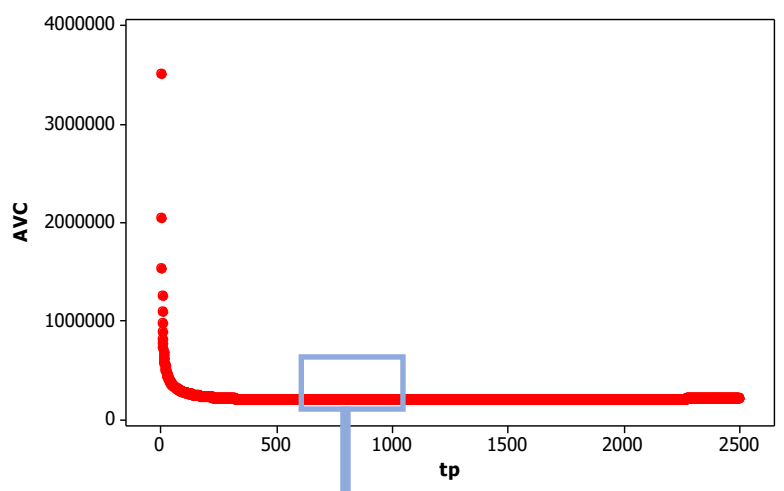

(a)

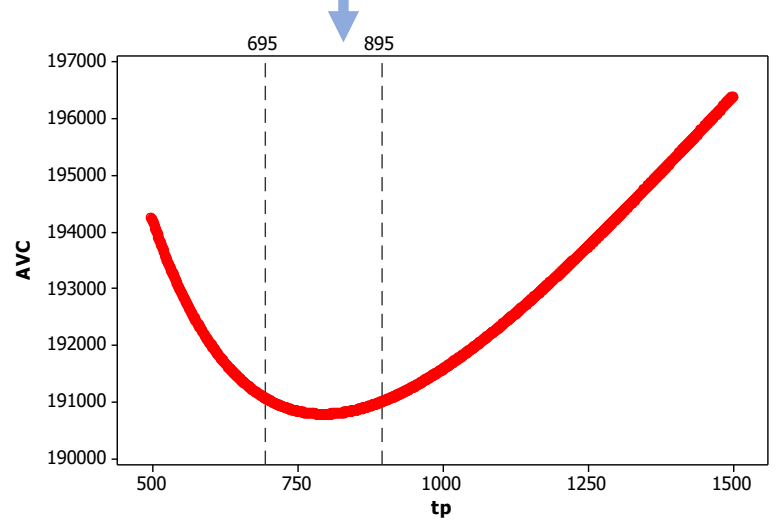

(b)

Gambar 3. Plot AVC terhadap tp

Gambar 3 menujukan hasil dari perhitungan AVC (Average Variable Cost) . Berdasarkan Gambar 3 dapat diketahui bahwa titik terendah kurva terjadi pada saat tp bernilai 795 jam sampai 1000 jam dengan estimasi biaya pemeliharaan sebesar Rp 190.776,5 sampai dengan Rp 191.560,2. Sehingga apabila ditinjau dari nilai tp dan estimasi biaya maka waktu preventive maintenace komponen yang optimum dapat dilakukan dalam kurun waktu 795 jam sampai dengan 1000 jam. Nliai $t_{p}$ tersebut sudah sesuai jika mengacu pada nilai MTTF setiap komponen, di mana nilai MTTF cutter sebesar 3094,25 dan nilai MTTF Selenoid sebesar 2599,81.

\section{KESIMPULAN DAN SARAN}

\section{A. Kesimpulan}

Berdasarkan hasil analisis diperoleh kesimpulan bahwa lifetime komponen cutter dan selenoid pada mesin Cing Fong $H$ berdistribusi weibbul 2 parameter. Pada perhitungan nilai dependensi didapatkan nilai $-0,009952381$ dan menghasilkan Copula terbaik dengan nilai parameter Copula terkecil sebesar $-0,01887$ yaitu pada Copula clayton. Sehingga didapatkan model reliabilitas dan didapatkan plot yang menjukan bahwa keandalan suatu mesin akan mengalami penurunan seiring bertambahnya waktu pakai mesin. Berdasarkan model reliabilitas didapatkan waktu optimum maintenance yang apabila ditinjau dari nilai tp dan estimasi biaya maka waktu preventive maintenace komponen yang optimum dapat dilakukan dalam kurun waktu 795 jam sampai dengan 1000 jam 


\section{B. Saran}

Pada penelitian ini faktor kerusakan mesin yang dianalisis terbatas pada faktor internal saja, namun kerusakan mesin juga disebabkan faktor eksternal sehingga pada penelitian selanjutnya sebaiknya juga memperhatikan faktor eksternal. Sebaiknya untuk memastikan titik optimum sebaiknya dilakukan dengan mencari turunan pertama dan turunan kedua dari fungsi AVC dan nilai AVC dihitung dengan syarat reliabilitas lebih besar dari $75 \%$.

\section{DAFTAR PUSTAKA}

[1] R. L. D. Putri, H. Pratiwi and D. R. S. Saputro, "Estimasi Parameter Distribusi Marshall-Olkin Copula dengan Metode Maximum Likelihood," in Seminar Nasional Matematika Dan Pendidikan Matematika UNY, Yogyakarta, 2016.

[2] R. B. Nelsen, An Introduction to Copula, New York: Springer, 2006.

[3] Á. Rózsás and Z. Mogyorósi, "The effect of Copulas on timevariant reliability involving," Structural Safety, p. 94-105, 2017.

[4] H. An, H. Yin and F. He, "Analysis And Application Of Mechanical System Reliability Model Based On Copula Function," Polish Maritime Research, pp. 187-191, 2016.

[5] E. A. Elsayed, Reliability Engineering, New Jersey: John Wiley and Sons Inc, 2012.

[6] W. W. Daniel, Statistik Nonparametrik Terapan, Jakarta: Gramedia, 1989.

[7] C. Jiang, W. Zhang, B. Wang and X. Han, "Structural Reliability Analysis Using A Copula-Function-Based Evidence," Computers And Structural, vol. 143, pp. 19-31, 2014.

[8] C. Guo, W. Wang, B. Guo and R. Peng, "Maintenance Optimazion For Systems With Dependent Competing Using A Copula Function.," Maintenance And Reliability, no. 15, pp. 917, 2013.

[9] C. Li and H. Hao, "A Copula-Based Degradation Modeling And Reliability Assessment.," Engineering Letters, vol. 3, no. 24, 2016. 